\title{
Teaching English Through Modern Technology: A Study of Private Language Centers, Sindh Pakistan
}

\author{
Shamim Kousar \\ University of Sindh (Mirpurkhas Campus), Pakistan \\ Shabana Sartaj \\ Sindh Agriculture University Tandojam, Pakistan
}

Syed Waqar Shah

Mehran University of Enineering and Technology, Pakistan

Shoukat Ali Lohar

Mehran University of Enineering and Technology, Pakistan

Received: March 3, 2019 Accepted: April 23, 2019 Published: April 29, 2019

doi:10.5296/elr.v5i1.14575 URL: https://doi.org/10.5296/elr.v5i1.14575

\begin{abstract}
In this modern world where everything is connected with new technologies and internet. Under control of the internet and new technological inventions, it is hard to undermine their contribution to foreign language teaching. This study pertains to the beginner level students doing English language diploma courses in their initial stage at a private English learning institute located in Sindh province of Pakistan. The study aims at investigating English teaching practices through SS method (Student to student) such as pair work and group study and reduce TS method (Teacher student) of teaching. In such methods modern technology such as visualizer and multimedia (modern technology) are great help for practicing a language teaching. The use of aids and tools is one of the useful resources for language learning and teaching in an easy manner. Most of the researchers' interest lies in action research and carried out different cycles of action research such as planning, acting, observation and reflection. The study used convenient sampling to recruit participants $(n=20)$. Data for the study included open-ended questionnaires, classroom observations and semi
\end{abstract}


-structured interviews from students as well as researchers' reflections as a supplementary source of data. The study finds multimedia usage crucial, especially by the young generation of language teachers who understand and support the idea of technology in the classroom, on the contrary to the older generation which criticizes and underestimates its importance.

Keywords: L2, Innovation, Modern technology, Action research, Pedagogical practices

\section{Introduction}

In most of the educational institutes of Pakistan L2 teachers and students do not have facilities of modern technologies and aids of learning such as multimedia, language learning websites, language laboratory and so on. For imparting good quality education to the students, the role of a teacher is vital. A teacher should not only be well-informed but he/she should be knowledgeable, skilled enough to teach students (Bijalwan, 2015). A teacher can make a favorable and learning based environment in the class and students can enjoy, appreciate, acknowledge along with learning. The role of a teacher is considered most important as students' learning entirely depends on teacher's expertise: if teacher is capable students will be learning with enjoyment, but if teacher lacks teaching skills, classes could not be enjoyable for them. Students trying to learn English as a second language need further language support. They need to practice in listening, reading, speaking, and writing language in order to develop their experience and skills (Ybarra \& Green, 2003). Their confidence also increase and they learn a great deal by doing so. As still the trend of traditional English language teaching is going to develop in students which helps a little to improve their English language skills so Bijalwan (2015, p. 710) devises two key concepts of the learner centered classroom. Initial one is placing greater responsibility in the hands of the students to deal with their own learning, and second, teachers taking roles as facilitators of knowledge to help learners learn how to learn rather than being the source of knowledge. Teaching with different ways teacher should rather be very expert at teaching field. This is possible once they are either involved in research or have rich experience of teacher educational instructor training course. Understandably, learning ought to be in a natural context; it should not be detached from the context learners are the part of. If they are, then the things will become imaginary to learn for them and harder to understand. The problem in Pakistan is that English serves as a Foreign Language (EFL), which requires time, rich EFL exposure extensive practice and so on. Leaving students to practice on their own, creating friendly and favorable environment in the class, making classes practice -based and activity -based and encouraging the learners at every sort of their feedback, rich or poor, will likely bring better results. As Sharma (2009, cited in Nomass, 2013, p. 111) says that the effect of technology has become huge in teaching and learning the language in addition to the instructor's role. In other words, the role of the teacher together with the role of the technology can lead to advanced learning outcomes.

\subsection{Significance of the Study}

This study is significant as it brings out pros and cons of using multimedia technology in English classes. It also helps to understand the needs of modern technological interventions for English Language Learners (ELLs) in a classroom setting. It further encompasses which methods and strategies are being applied by ESL teachers to encourage students in learning English language. Finally, the study explores how technology can potentially help students achieve communication skills. 


\subsection{Aims \& Objectives}

The aim of study is to investigate how far technology facilitates teachers and students to improve English language teaching and learning practices. The following objectives were chosen;

1) To investigate the challenges L2 teachers and learners face in using technology to learn English as a foreign language

2) To explore strategies and pedagogical resources L2 Teachers use in teaching English Language

\subsection{Research Questions}

1). What effects does the use of supplementary audio-visual material have on children's engagement in English language learning?

2). What methods or strategies English language teachers use to help English Language Learners (ELLs) be engaged in the class?

\section{Literature Review}

Technology and English language education are co-related with each other (Singhal, 1997). Before $18^{\text {th }}$ century, English language learning laboratories were being utilized as a part of different educational institutions. The traditional language laboratory was comprised of various little cupboards, gave a tape deck, an amplifier and an earphone for everyone. Teachers utilize focal control to monitor their students' interactions. The fundamental favorable position of that kind of innovation was that verbal conduct of students would push them to rapidly learn the second language. The students' skills can be upgraded by encountering more practical drill problems. There is no doubt the language laboratory was a positive step in linking technology and language training, this system was really dull and exhausting for students (Singhal, 1997). Likewise, there were insignificant collaborations between the instructor and his understudies. PC helped dialect learning (CALL) programming has given another instructing apparatus to second dialect training. The use of computers in English language classroom is helpful for both teachers and students. Currently, there are various programming application programs accessible, for example, vocabulary, syntax and articulation programs, spelling check utilities, electronic exercise manuals, perusing and composing programs, and distinctive learning bundles to help teachers in making instructional exercise activities to improve their English dialect courses.

Students trying to learn English as a second language need further language support. They have to rehearse in hearing dialect, perusing dialect, talking dialect, and composing dialect with a specific end goal to build up their experience and abilities (Ybarra \& Green, 2003). For doing such tasks, they are in need of using various tools. Which can enable them to take in the dialect effortlessly and viably? The term New Technology includes communication techniques for language teaching in which the personal computer plays a main role (Davies \& Hewer, 2012). The results show that most of the students preferred the use of technology, especially computers, in developing their second language learning. Thus, Nomass (2013) in language teaching, evaluation plays a role as a feedback for learners and the course achievement (Dudley-Evans \& ST John, 1998). Researcher chose action research for study since it is quite unique from traditional research and it aims at solving immediate problems. 
According to Bughio (2012, p. 67), Thus the researcher problematized the situation and developed an action plan to solve the issues. For this purpose, action research carried a systematic investigation, which helped to develop a thorough understanding of problematic circumstances. As Elliot (1991, cited in Burns, 2010, p. 16) described, it is the study of a social situation with the view to improving the quality of the action in it. Teacher action research is defined as systematic inquiry of the issues by teachers with the goal of improving their teaching practices. (Rock\& Levin, 2002, p. 08) Vice versa technology has impacted the learning approaches and to improve the standard of teaching and language learning (Somoro 2018) thus the literature reviewed points out that Action Research aims at improving educational practices by a systematic investigation. Therefore, Burn (2010, p. 08) it stated that Action Research as a systematic inquiry based on these steps like, observe, act, observe and reflect. She characterized them along this way:

a) Plan: In the first step, the researcher builds an action plan after observing the situation.

b) Observe: In this step, the researcher makes deliberate interventions having observed the situation so as to put those plans into activates and then implements them into the context $\mathrm{s} / \mathrm{he}$ is in.

c) Act: Here the researcher goes for a systematic observation to see the effects of the lessons and actions planned by him. To avoid biasedness, he involves participants of the study so as to get their feedback regarding the lessons.

d) Reflect: Here the researcher reflects back on his teaching, evaluates all those actions and describes whatever he sees during the observation.

So, the Action Research is a systematic way to deal with any kind of problem taking place in the classroom. As the most researchers' concern is classroom and its issues, so the trend of adopting action research is said to be increasing in Pakistan. As Bughio (2012, p. 84) claimed that action research investigation is turned out to be compelling in an educational setting. It is powerfully effective in a way that it gives a broader understanding of the problem and subsequently promotes educational practices by resolving the common issues. In this way, the quality of education also enhances which helps action research practitioners to develop in their teaching profession since they actively involve themselves in cycles of action research. Bughio (2012, p. 86) agreed with Rasul (2009) regarding her views on action research in Pakistan and he believed that there is need for systematic and long term planning to introduce and inculcate the culture of research. As the research reviewed above clears that Action Research brings about reforms in education so I believe that it will contribute to a great extent to the phenomenon in the at Knowledge Gate Institute of Academic Success, Mirpurkhas.

\section{Methodology}

\subsection{Qualitative Data}

Qualitative paradigm of research was taken for this study. In order to have an in -depth understanding of the problems, the researchers identified three language classes of beginner level so as to know how English language teaching goes on there. The researchers also developed perception regarding language teaching and learning processes that were going in the classroom. In order to support the study, the researchers used research instruments like, semi -structured interviews forboth the students and the teacher. They used open -ended 
questionnaires from the students, classroom observations were conducted, researchers' reflections were also given and action research cycles were made part of this exploration.

\subsection{Site of the Study}

This study was conducted at Knowledge Gate Institute, Mirpurkhas which is an English language center. Knowledge Gate Institute offers different levels in General English course like, beginner, intermediate and advance, English Speaking Club, Children's Speaking Club, English Writing Club and International English Language Testing System (IELTS). 20 students of beginner level were involved in the study.

\subsection{Action Research}

In action research, practitioners identified the issues which are related to their practice and closely work with colleagues to solve the issues of immediate concern. The essence of action research is, hence, practical improvement with the intention of continuing these improvements through research and process of action.' Action research provides a practical framework to address the problematic situation systematically, which traditional research cannot sufficiently provide. (Bughio, 2013, p. 71).

\section{Data Collection Procedure}

Following the research ethics, permission was taken from teacher who was already taking the class. He was discussing about grammar and tenses were made concentration during the class. The teacher was teaching them how to identify the tenses. He gave identification clues of each tense one by one along with their examples in English as well as Sindhi language. After he was done the identification clues of the tenses, he asked the helping verbs of different tenses from the students by giving them sentences. This occupied not less than thirty minutes, In last ten minutes, he revised the tenses again and thus the class was ended.

On the other day, the teacher distributed some handouts among the students when he entered the class. Sindhi language sentences were being used in those handouts. Like day first, the second day was all about tenses in which the teacher asked the students different sentences of different tenses from students and asked them to identify the sentences which tense belonged to which sentence. It was the way, as he kept questioning asking about the tenses. The aim of this activity was to judge students understanding about tenses how far the students identify tenses.

On last and third day, the teacher did nothing but repeated the same activity he kept asking different forms of verbs used in different tenses. Apart from that, he gave different Sindhi sentences to translate in English than he started the translation activity and he repeated same activity till to the end of the class by students.

It was observed that his classes were based on grammar. Each activity was grammar based; teacher did not use communicative activities during the class at all. Students were not getting interest in such method of language teaching. Since English does not mean grammar; rather there was complete lack of English language skills in class while it is all based on about English language skills. Teachers' traditional method of teaching grammar did not let students be fluent and good at communicative skills. The main reason of harming student's language development is such sort of traditional approaches of teaching English.

After been familiar with the problem in the context, the researchers developed a thorough 
understanding of the problem. In addition to it, the betterment of teaching and learning required planned lessons and connection with the problems.

\subsection{Preparing Lesson Plans}

The researchers prepared three lesson plans keeping in mind learners' level and needs. As their purpose of joining these courses was to acquire proficiency in English language, so researchers planned lessons accordingly so as to meet their needs. Researcher had to make sure that all the lessons should have some objectives to be fulfilled at the end of each lesson. Researchers got help from modern technology, like multimedia and speakers. Researcher conducted interviews from the teacher and the students also. Researcher got quite clear vision of the teacher's teaching method from the interviews of both.

\subsection{Implementing Lesson Plans and Their Reflections}

\subsubsection{Implementing Lesson One}

The researchers designed some lessons to implement in the classroom keeping in mind the students' level. As the students were not used to watching any video, so the first lesson was started with a video on multimedia. Through multimedia, students get exposure of watching native speakers of English. To make lesson interesting, informative and goal -oriented, video was used and played on the projector. The video was all about 'The Greatest Treasure'. To make it easier, the transcripts of dialogues of that video were also given to the students and asked one of the students to distribute among them. This way, the lesson started. The students were informed about the video and asked to repeat whatever they listen. In addition to this, the researcher also kept explaining them the story. All the students watched the video with great enthusiasm and repeated sentence by sentence. After they were done with the video, they were asked to sit in pairs and discuss the idea they got from the story. They sat together and began their discussions. At the end, their comments were noted and observed.

\subsubsection{Reflection of Lesson One}

In first lessons, the students got exposure to listen and watch native speakers of English which they never get at their language classes of beginner level; rather they all the time do grammar exercises. With innovation in teaching, they did enjoy the class and there was a pin drop silence in the whole class. Every student was enjoying the video. Afterwards, they learnt the use of words used in the story. They were asked to give use of those all new words they got from the story. The researchers already had underlined the new words because they had planned to teach them vocabulary also. This way, the first lesson aimed at building their vocabulary in context. Vocabulary could better be built through stories and novels where one can find the context. This pattern of teaching vocabulary was effective for the students. Also they learnt about pronunciations and got different lessons from the story. Afterwards, they matched those examples with their practical lives. Pair discussion on the story also provided them a platform to make discussions freely and bridge the information gap. After the discussion, when they were called on the stage to share lessons they learnt from the story, their improvement was visible.

\subsubsection{Implementing Lesson Two}

The lesson two was all about the conversational skills. For this, computer and loud speakers were used. First, the students were briefed what conversation is and then I explained those 
different ways of effective conversation. I explained them that conversations are situational, like between teacher and student, doctor and patient, husband and wife, two friends, etc. Since it was beginner level, so the language of instruction was English but sometimes, the instructor/researcher switched the code from English to Sindhi so as to make them understand the things. The situation that was played for the students was about 'Inquiring about health'. For their better understanding, the transcripts of the dialogues were distributed among them. In that situation, there were three dialogues. The students were asked to repeat whatever they listened. All the students repeated the dialogues in chorus. During these dialogues, it was observed that students were more energized. After the students were done with the listening of the dialogues, they were asked to sit in pairs to make dialogues on any situation they want. They sat in pairs for discussion for about 10 minutes. Afterwards, they were asked to sit properly and start their dialogues pair by pair in front of all the students. They were given free hand in terms of making dialogues on any situation. All students came forward in pairs and performed their dialogue. Since the class was being recorded so girls avoided coming for dialogue performance. Girls were too shy to come in front.

\subsubsection{Reflection of Lesson Two}

As this was an interactive lesson, the students were excited in this class too. The researchers used computer, loud speakers and brought material on the lesson also. The students' response seemed to be better than before. After listening to dialogues on speakers, when they began making discussions in pairs, they were enjoying that part of discussion. This is why; they brought very interesting situations and performed on the stage. This way, they learnt a great deal, came forward and performed excellently. Consequently, their confidence kept building which, in turn, inspired others to participate actively also. The lesson went well till the end. They were found to be enjoying every moment and making fun with one another.

\subsubsection{Implementing Lesson Three}

Lesson third and the last was 'knowing about using different websites for language learning' like, YouTube and Ted Talks. First, it was planned to inform students about the usage of You Tube. We explained them the benefits of using this website in terms of language learning. Some videos were shown to them by clicking 'English Videos' in the search bar. There came a number of videos. All the students watched everything with keen interest. Once the demonstration of Youtube was done, Ted Talks was turned on. Like You Tube, the function of Ted Talks was also demonstrated. Students were told that that it was a bit different from You Tube in a way that it has different themes given in the menu like, education, business, science, etc. they were showed a video by selecting the theme 'Education' and were told one thing important about Ted Talks that was all the videos had their transcriptions which could be saved in Word file. This way, one video was chosen and brought its text on Word file. Then the downloaded video was played, while the transcription was displayed on Multimedia screen. Though the fluency rate in the video was a bit faster, yet the students could understand it by reading the text on Multimedia screen.

\subsubsection{Reflection of Lesson Three}

This lesson was an interesting source of learning for the students. Psychologically speaking, students love to watch videos so these were going to create fun for them. This way, they 
could have rich exposure to native speakers of English with frequent practice. Extensive visit of You Tube could better their listening and speaking skills. Making discussions after watching videos did boost up their confidence. As for Ted Talks, it was much better than You Tube for the students since it carried transcriptions also. As the students were from beginner level, so they needed both the videos and their transcription in initial phases of language learning. After downloading a video from Ted Talks with its text, the students were asked to go through the text and listen to the video simultaneously. Once they were done with it, they saw those videos which were played and after that removed the text. They listened to it and when the researchers took their feedback, the comprehension was good enough. This way, the use of modern technology helps in English language learning.

\section{Findings of the Study}

Factors Influencing the Communication are:

\subsection{Cultural Diversity}

It was when individuals from various social foundations impart the possibility of misconception and wrong understanding of the message is higher. Study finds that students from different backgrounds face difficulties while communicating with each other.

\subsection{Misunderstanding of Message}

The correspondence in classroom additionally falls flat when individuals appoint distinctive implications to a similar word. Such misconstruing happens when specialized words or languages are utilized. In addition, individuals may deliberately confound the internal significance of words. It happens when sender does not clarify its message. They watched the video and learnt new words along with their use. They were also taught the art of guessing the meaning of unknown words from the context.

\subsection{Emotional Difference}

Emotions and sentiments of the gatherings engaged with correspondence essentially influence the significance of correspondence. For instance, doctors are generally less passionate to the patient than those of the relatives of the patients.

\subsection{Past Experiences}

The experience of past correspondence emphatically decides the viability of further correspondence between a similar sender and beneficiary. On the off chance that both of the gatherings has unpleasant experience, encourage correspondence between them is probably going to be ineffectual.

\subsection{Educational and Intellectual Difference}

The distinction in formal instructive and scholarly level of sender and recipient additionally impact the importance of correspondence. In the event that they have comparable instructive capabilities, correspondence will be successful. Since they are probably going to hold comparative observation, understanding, feeling, considering, see and so forth.

\subsection{Positional Differences Among the Personnel}

On the off chance that sender and recipient hold distinctive positions in the order, correspondence between them may fizzle. Some of the time we see that to maintain the custom it the association, a few people goes too far. 


\subsection{Functional Relationship Between Sender and Receiver}

The functional relationship between sender and receiver significantly affects the meaning of communication in business. If sender and receiver belong to different functional departments or areas, the receiver may not understand the sender's message. For Example, students from higher level may not understand point of you from lower level.

\section{Discussion and Conclusion}

There are three lessons which are based on the reflections, and it defines that modern technology makes learning of English easier as compared to grammar -based language teaching at English language centers of Pakistan generally and Mirpurkhas particularly. The proper use of modern technology provides rich exposure of native speakers of English for EFL students. It was observed that untrained and traditional teachers of English only focus on grammar. Generally, they are of the opinion that it is only grammar that helps in learning English. To them, grammar is everything. Even they teach vocabulary by providing lists of words to students and ask them to cram it. Proficiency in English does not come through by cramming long lists of vocabulary and rules of grammar. As the way I taught vocabulary to the students was effective in a way, it taught them vocabulary in context of a story "The Greatest Treasure'. Likewise, vocabulary of English can be taught be taught in context. Secondly, the use of multimedia and speakers attracted the students' attention toward learning. They were very much excited to see video being played on the screen and listen to their pronunciations. What happens here is that students do not get that rich exposure in terms of listening to native speakers of English with pronunciations. The observation of the second lesson proved to be more effective and interesting for the students than the previous one in a way that the second lesson carried interactive dialogues on different situations. By involving students into interactions in pair and group discussions, information gap is bridged, shyness is removed, confidence level is built up and knowledge about social issues is generated. Psychologically speaking, students get fed up with monotonous teaching; they want some change in pedagogy. Teaching with innovations and modern methods equipped with modern technology remains successful, as went mine, in achieving your objectives. While watching the dialogues on screen, the students cheered and knew different ways of starting dialogues, taking turns and winding up the dialogue. When they were put into discussions, the result was that they came forward to perform the dialogue with enthusiasm. They were found to be enjoying the every moment during dialogue performance. This way, active engagement of students into interesting discussions raised their morale and encouragement. Using technology with already -made - planning entirely changes the classroom scenario and the classroom becomes an ideal place of learning by doing so. The availability of the material coupled with dynamic teaching maximizes learning to a great extent. Access to internet and useful websites of English language learning proved to be an easy source of learning. Language learning websites like, You Tube and Ted Talks enable students to have expertise in listening as well as speaking. What happens in our context is that students are rarely provided with the availability of these websites. As they don't listen to neither native speakers nor watch them while speaking, so understanding them becomes problems for them. Consequently, they are not good at pronunciations, listening and speaking. The study proved to be successful in obtaining the intended targets; simplifying the language through 


\section{Macrothink \\ Education and Linguistics Research \\ ISSN 2377-1356 2019, Vol. 5, No. 1}

technology was the main target.

\section{Suggestions and Recommendations}

a) Teachers Should Play the Leading Role in Teaching

b) Teachers Should Not Consider the Computer Screen as a Blackboard or Whiteboard.

c) Teachers Should Encourage Students to Use their Own Mind and Speak.

d) More Teachers Should Use All Possible Teaching Aids and Techniques.

e) Teachers should not overuse Multimedia Technology.

\section{References}

Bijalwan, R. (2015). Teaching English Language through Modern Techniques and Literature published. International Journal of Literature, English Language and Humanities, III(IV).

Bughio, F. A. (2013). Improving English language teaching in large classes at university level in Pakistan (Doctoral dissertation, University of Sussex).

Burns, A. (2010). Doing action research in English language teaching: A guide for practitioners. Routledge. https://doi.org/10.4324/9780203863466

Elliot, J. (1991). Action research for educational change. McGraw-Hill Education (UK).

Hoven, D. (1999). A model for listening and viewing comprehension in multimedia environments. Language Learning \& Technology, 3(1), 88-103.

Nomass, B. B. (2013). The impact of using technology in teaching English as a second language. English Language and Literature Studies, 3(1), 111. https://doi.org/10.5539/ells.v3n1p111

Rasul, S. (2009) Action research: A prospective tool for empowering Pakistani teachers published. The Pakistan Journal of Social Issues, 1(1).

Rock, T. C., \& Levin, B. B. (2002). Collaborative action research projects: Enhancing preservice teacher development in professional development schools. Teacher Education Quarterly, 29(1), 7-21.

Sharma, P. (2009, April 8). Controversies in using technology in language teaching. Retrieved from http://www.teachingenglish.org.uk/articles/controversies-using-technology-languageteaching

Soomro, F (2018) Teachers and Technology Trends in English language teaching in Saudi Arabia.

\section{Copyright Disclaimer}

Copyright reserved by the author(s).

This article is an open-access article distributed under the terms and conditions of the Creative Commons Attribution license (http://creativecommons.org/licenses/by/3.0/). 